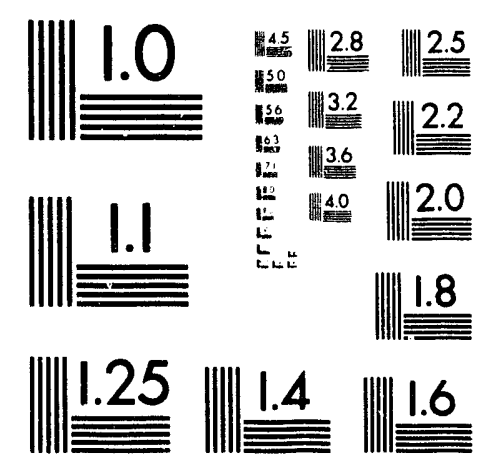



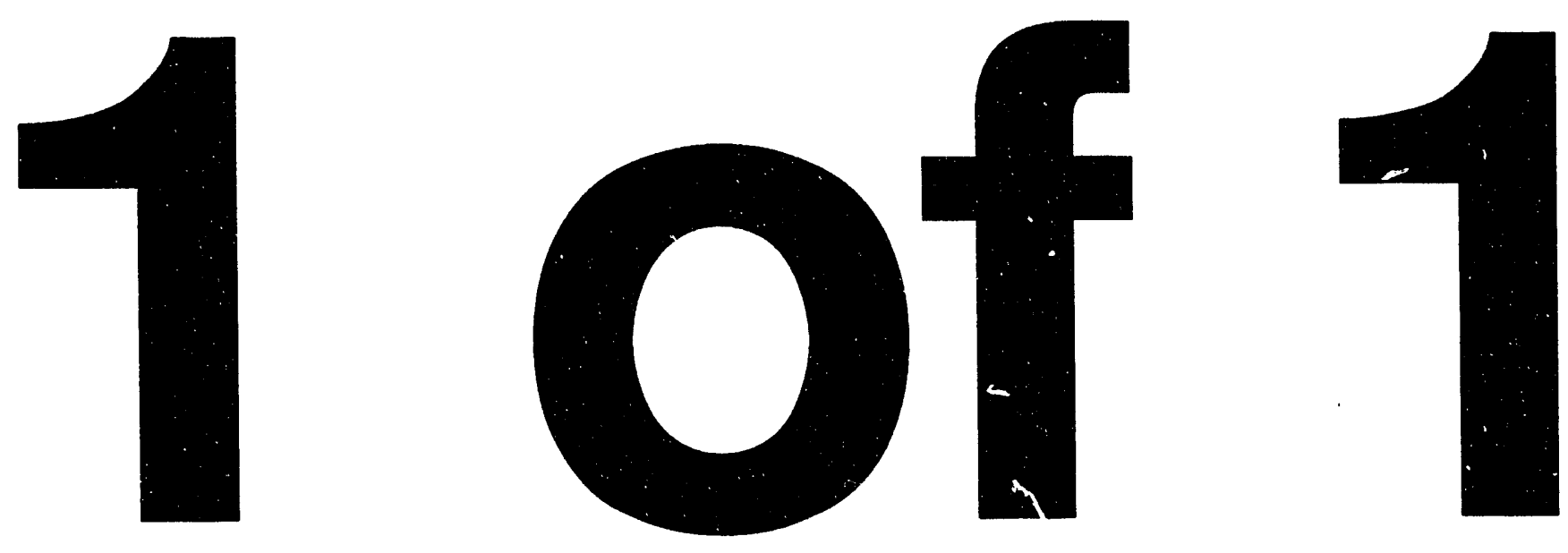
TITLE: COMMENTS ON: "THE USE OF CONDITIONAL SIMULATION IN NUCLEAR WASTE SITE PERFORMANCE ASSESSMENT"

AUTHOR(S): Joanne Wendelberger/Richard Beckman

\section{DISCLAIMER}

This report was prepared as an account of work sponsored by an agency of the United States Government. Neither the United States Government nor any agency thereof, nor any of their employees, makes any warranty, express or implied, or assumes any legal liability or responsibility for the accuracy, completeness, or usefulness of any information, apparatus, product, or process disclosed, or represents that its use would not infringe privately owned rights. Reference herein to any specific commercial product, process, or service by trade name, trademark, manufacturer, or otherwise does not necessarily constitute or imply its endorsement, recommendation, or favoring by the United States Government or any agency thereof. The views and opinions of authors expressed herein do not necessarily state or reflect those of the United States Government or any agency thereof. 


\title{
Comments on: "The Use of Conditional Simulation in Nuclear Waste Site Performance Assessment"
}

\author{
by
}

\section{Joanne Wendelberger \\ Richard Beckman}

Professor Gotway is to be congratulated on her lucid and interesting application of spatial statistical techniques to the important problem of groundwater transportation through the Waste Isolation Pilot Plant (WIPP) in Southeastern New Mexico. In the assessment of underground storage of nuclear waste, one of the greatest concerns is encroachment of the repository and transportation of radionuclides from the repository to the surrounding environment by the groundwater. This paper demonstrates the contributions that can be made in the studies of this important problem and similar problems of national importance by the application of modern statistical techniques. In the comments that follow, our intent is to highlight those areas where some additional study would strengthen this application.

It almost strikes one as ludicrous that there would be much confidence in a model that is used to predict physical characteristics of the Earth 1,000 to 10,000 years in the future. (One of the authors of these comments is guilty of such modeling, Crowe, Jor son and Beckman, 1982.) Due to government regulations which are driven by the long half-lives of the radioisotopes involved, studies of radioactive waste disposal must necessarily involve predictions over long periods of human time which, however, are short periods of geologic time which are likely to be stable. Since such long time periods are involved, it is commendable that Professor Gotway 
includes in her study the cumulative distribution function (CDF) of the groundwater travel times (GWTT) determined by a simulation model. Her Figure 13 shows this CDF. Thus, an indication of the expected variability in the GWTT is given. However, the variability represented in Figure 13 does not include, what we shall call here, the uncertainty in the predicted CDF. This uncertainty is due to incomplete knowledge of the simulation model itself. To reiterate a point in Professor Gotway's summary, the changes in the CDF of the GWTT as a function of the model assumptions and the variability of the estimates of the parameters which drive the simulation model should be assessed. Considering the model uncertainty in addition to the simulation variability may be critical in the study of GWTT at WIPP, since the CDF of these times takes a jump at one of the Environmental Protection Agency's critical times, 10,000 years.

It is of course impossible to include all the uncertainty present in the model, but some contributors to this uncertainty are obvious and should be addressed before the final results are accepted. The CDF of the GWTT relies on many assumptions and the estimation of numerous parameters. Most of these estimates and assumptions are given without questioning their influence on the final result and with minimal model checking. For example, what is the sensitivity of results in the author's Figure 13 to the transmissivity value of $\log _{10}(T)=-10.12$, the Gaussian assumptions, the deterministic modeling of the flow through a confined aquifer, the calibration adjustment to the observed pressure data, the turning bands methodology and, maybe most important, the semivariogram estimation technique?

We quickly comment on some of the areas for uncertainty studies given above and comment more extensively on the estimation of the semivariogram. The transmissivity model, which 
includes both the adjoint-sensitivity approach of LaVenue and Pickens (1992) and the confined aquifer flow model of LaVenue et al. (1990), is extremely intricate and the contributions of the input variables of this model to the uncertainty in the estimated CDF of the GWTT are not clear. However, it is clear that parameter inputs to equation (5.1), such as rock porosity, fluid viscosity, and fluid density are not known with certainty. It would have been an easy task to include this variability in the simulation study.

A study of the methods for the generation of nonnormal, nonindependent multivariate data sets can be complex (see Johnson, 1989). Given the nonlinear characteristics of most nongaussian distributions, the transformation of such multivariate data sets into surfaces exhibiting a given spatial covariance structure may be difficult if not impossible to accomplish. This should not however prevent us from questioning the influence of the Gaussian assumption. Are there ways to bound its influence on the resulting groundwater trarısportation times?

Professor Gotway recognizes that the turning bands method introduces error in the covariance function due to the finite number of randomly drawn lines and their placement. It is not clear from her discussion however if the uncertainty in the generation of the simulation data caused by the placements of the lines is reflected in her estimated CDF. If a new set of randomly selected lines were generated for each of the 44 simulation runs, then this uncertainty in the data generation is inc:uded in the computed CDF. If the same randomly selected lines were used for each simulation run, then the uncertainty in data generation is only partially exhibited in the CDF of the GWTT. One may also ask if the covariance structure influences the convergence rate of the turning bands method and thereby changes the uncertainty in the GWTT. 
For both the North-South and East-West directions two estimates of the empirical semivariogram were made. One estimate was based on a robust estimator of Cressie and Hawkins (1980), while the other was a method of moments estimator of Matheron (1963). These empirical semivariograms were then fit to the author's equation (3.6). It should be noted that in the East-West direction the transmissivity value, $\mathrm{T}=10^{-10.12}$, influenced one of the estimated points of the empirical semivariogram and that point was excluded from the fits for this direction. The transmissivity value, $T=10^{-10.12}$, is interesting. Being three orders of magnitude lower than the next closest transmissivity value, one would suspect that it would have a large influence on the estimated semivariogram, which in turn would influence the distribution of the GWTT. In this study however this uncertainty is not reflected in the final results.

The two estimated semivariograms are noticeably different. These discrepancies are shown in Figure 1, where the difference between the robust estimate and the method of moments estimate is given for the two directions. From this plot and the estimated sills in the EAST-WEST direction, $\hat{\mathrm{c}}_{e}=8.92\left(\mathrm{~m}^{2} / \mathrm{sec}\right)^{2}$ for robust estimator and $\hat{\mathrm{c}}_{e}=6.25\left(\mathrm{~m}^{2} / \mathrm{sec}\right)^{2}$ for the method of moments estimator, there is at least $30 \%$ difference in the estimated semivariograms at distances greater than $18 \mathrm{~km}$. Similarly, there is a $20 \%$ difference in the estimated semivariograms in the NORTH-SOUTH direction. Inclusion of the outlying point in the estimator could make this difference larger.

The transformation from the directional semivariograms to an anisotropic semivariogram is given in the author's equation (3.8). Figure 2 shows the final estimated anisotropic semivariogram for the angles $\phi=0, \pi / 8, \pi / 4$, and $\pi / 2$. Superimposed on these are the directional 
semivariograms for the NORTH-SOUTH and EAST-WEST directions. The difference between the directional and the anisotropic semivariograms is striking. The anisotropic semivariogram for the directions $\phi=0$ and $\pi / 2$, which correspond to the EAST-WEST and NORTH-SOUTH directions, are not only different from their directional semivariograms, but they are in a reversed order! One assumes that differences as large as these in the semivariogram would have a deleterious effect on the estimated CDF of the GWTT.

The model of the semivariogram influences the estimated groundwater transportation times. However, the extent to which the results are sensitive to the estimate of the semivariogram is not clear. Since Professor Gotway had multiple estimates of the semivariogram, she should have shown the sensitivity of her results to changes in the semivariogram on the order of those given in Figures 1 and 2 . In particular, faced with the differences in the directional and the anisotropic semivariograms, it would have been better to use the methods of zonal anisotropy which Professor Gotway mentions in section IV.

Professor Gotway is thanked for bringing such an interesting paper to the statistical community. The conditional simulation methods shown in the paper should be of great help to those faced with similar problems. Some practical considerations which would need to be addressed before applying these ideas to other problems include data requirements, difficulty of implementation, selection of the number of lines for the turning bands method, choosing a covariance model, the number of simulations needed, and the identification and performance of alternative methods. Our major disagreement with this study is that it does not go far enough in detailing the uncertainties in the final results. We realize that two days of computing on the 
same problem seems excessive. However, the incremental cost of additional CPU cycles is essentially (other than the time involved) zero. Even if a full month of computing is needed to do a sensitivity and uncertainty analysis, this extra computer time would be of little consequence given the importance of the safe storage of nuclear waste. 


\section{References}

1. Cressie, N. and Hawkins, D. M. (1980), "Robust estimation of the variogram," Journal of the International Association of Mathematical Geology, 12, 115-125.

2. Crowe, Bruce M., Johnson, Mark E., and Beckman, Richard J., (1982), "Calculation of the probability of volcanic disruption of a high-level radioactive waste repository within southern Nevada, USA." Radioactive Waste Management and the Nuclear Fuel Cycle, 3(2), 167-190.

3. Johnson, Mark E., (1987), Multivariate Statistical Simulation, John Wiley \& Sons: New York, New York.

4. LaVenue, A. M., Cauffman, T. L., and Pickens, J. F. , (1990), "Ground-water flow modeling of the Culebra Dolomite: Volume I-Model Calibration," Contractor Report SAND89-7068/1, Sandia National Laboratories: Albuquerque, NM.

5. LaVenue, A. Marsh, and Pickens, John F., (1992), "Application of a coupled adjoint sensitivity and kriging approach to calibrate a groundwater flow model", Water Resources Research, 28, 1543-1569.

6. Matheron, G. (1953), "Principles of geostatistics," Economic Geology, 58, 1246-1266. 


\section{Figure Captions}

Figure 1. The differences in the estimated semivariograms between the robust estimate and the method of moments estimate for each of the directions EAST-WEST and NORTHSOUTH. The difference between the two estimates in the EAST-WEST direction is as great as $30 \%$.

Figure 2. The two semivariogram estimates are shown as a function of distance. The directional semivariograms are given for both the EAST-WEST and NORTH-SOUTH directions. The anisotropic semivariogram is given for $\phi=0, \pi / 8, \pi / 4$, and $\pi / 2$. The directional and the anisotropic semivariogram estimates are very different. The order of these estimates for the two directions EAST-WEST $(\phi=0)$ and NORTH-SOUTH $(\phi=\pi / 2)$ is reversed in the two types of estimates. 


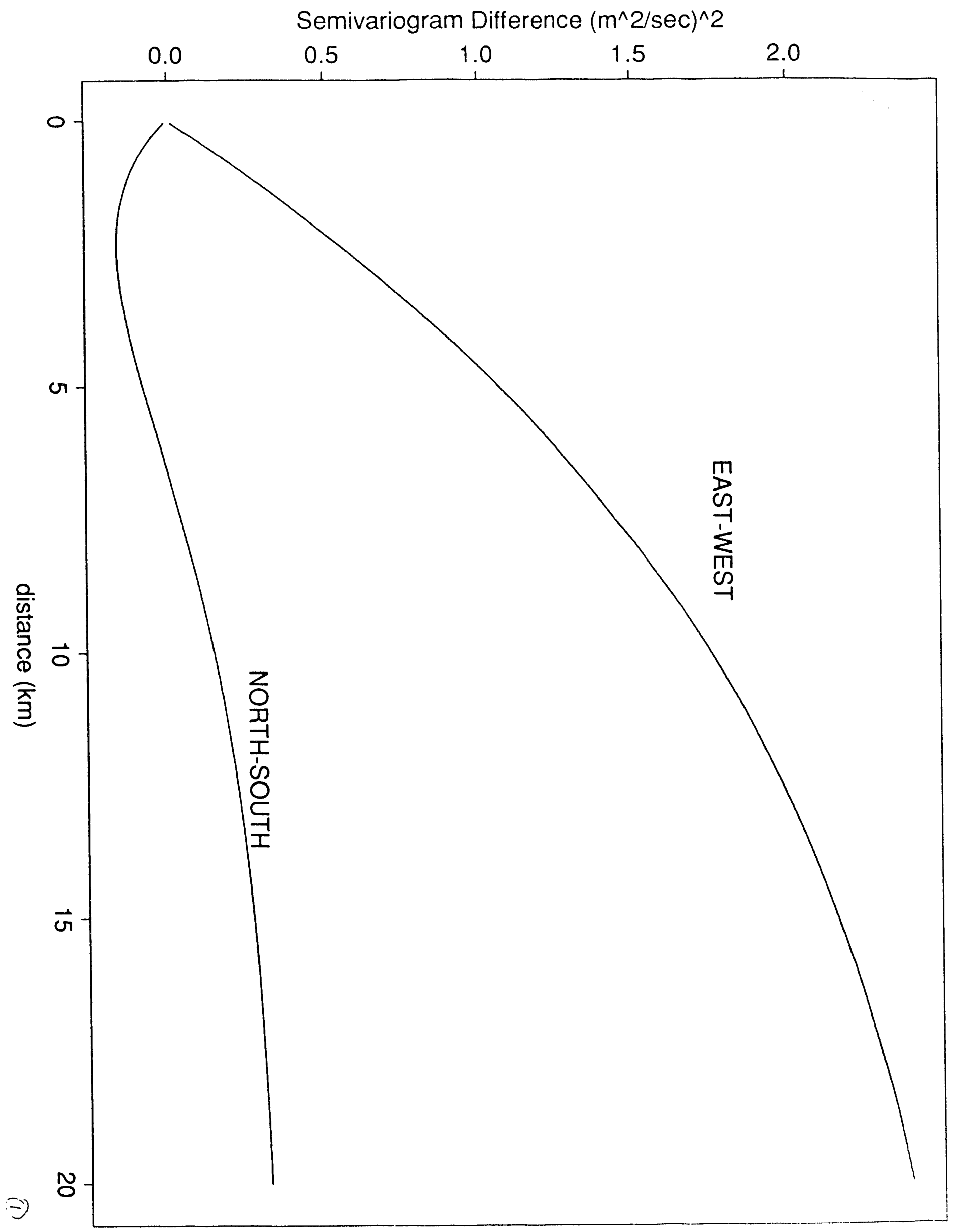




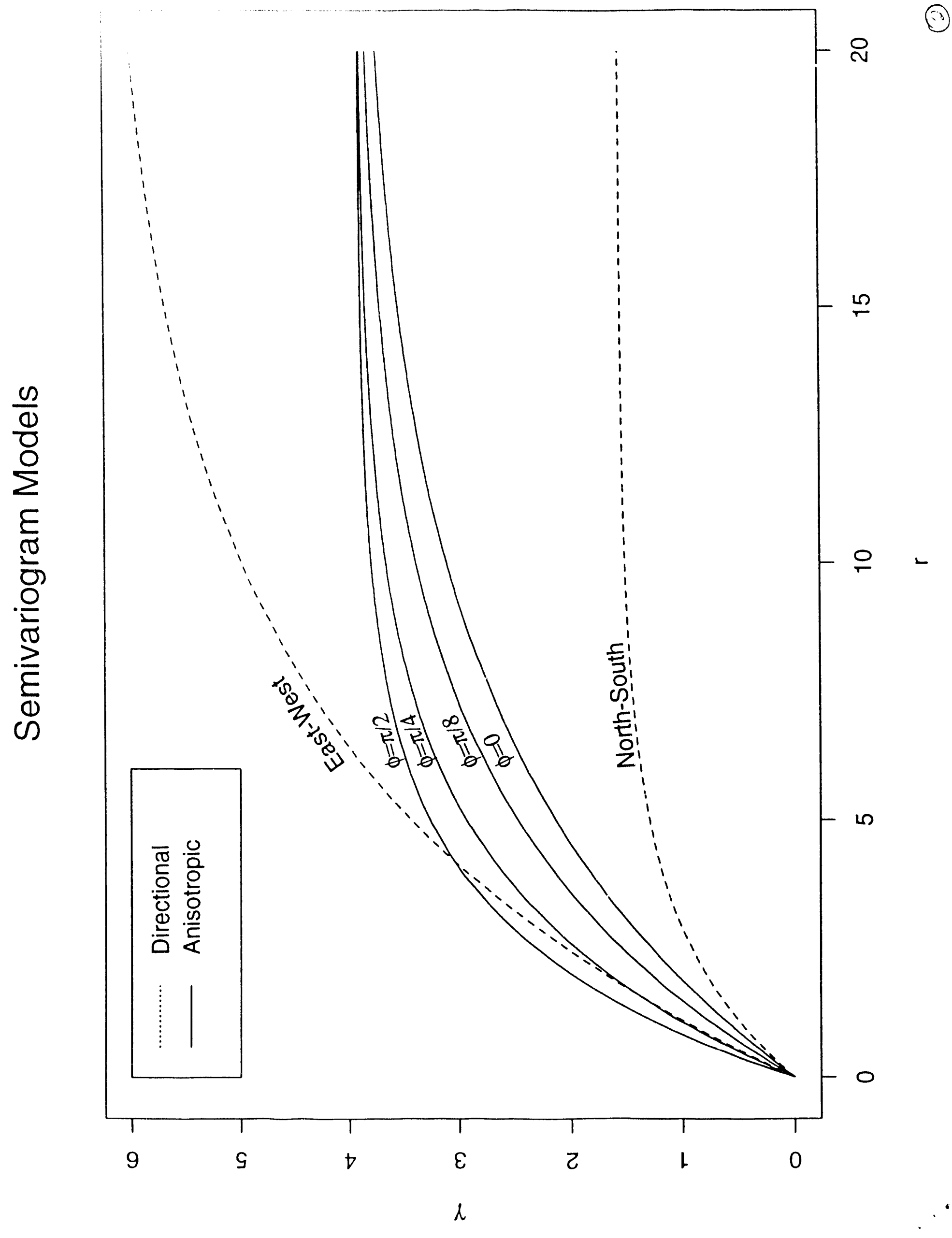



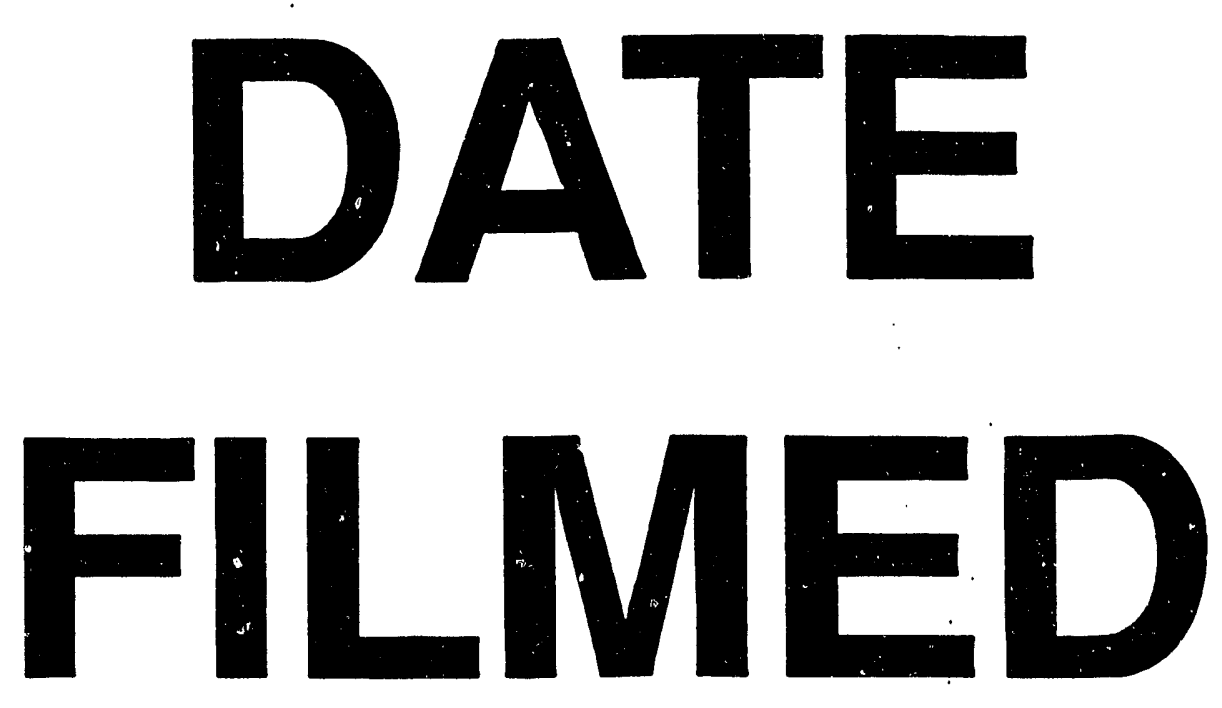

$9 / 28 / 93$
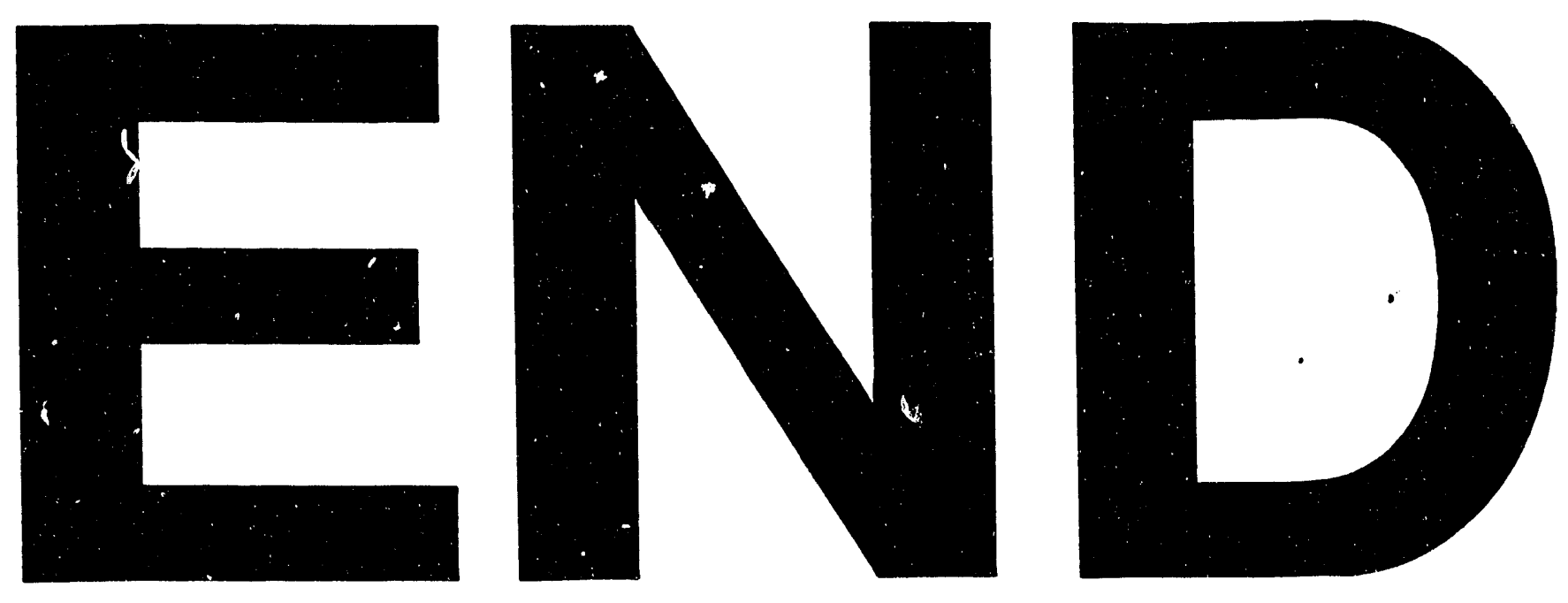
